\title{
Role of endoscopic ultrasonography
} in the diagnosis of solid pseudo-papillary neoplasm: Egyptian multi-centric case series and systematic review

\author{
Hussein Okasha', Wael Abbas ${ }^{2}$, Ahmed Altonbary ${ }^{3}$, Hazem Hakim ${ }^{3}$, Mahmoud Gamal Ameen ${ }^{4}$ and \\ Mohamed El-Nady ${ }^{1 *}$ (D)
}

\begin{abstract}
Solid pseudo-papillary neoplasm (SPPN) is a rare type of pancreatic tumor accounting for less than $2 \%$ of all pancreatic neoplasms. Accurate diagnosis of these tumors is very important for proper management. In this study, observations were documented from 18 consecutive cases diagnosed with SPPN using endoscopic ultrasound-guided fine-needle aspiration (EUS-FNA). The data of 18 consecutive cases were prospectively collected and reviewed. The collected data included age, gender, symptoms, size and site of the lesion, and type of surgery performed, in addition to mortality and recurrence rates.

The mean age of the included cases was 33 years, and most of them were females (94.44\%). Abdominal pain was the common symptom, and the pancreatic body was the most affected site. EUS-FNA confirmed the diagnosis in all cases when compared to the surgical specimen obtained. Cases were treated either with pancreatico-duodenectomy or distal pancreatectomy. One case (1/18) had early postoperative mortality due to sepsis. The remaining cases developed no recurrence or metastasis during the follow-up period of 18 months.

SPPN is not a common pancreatic tumor. Confirming the diagnosis plays a crucial role prior to surgery as it facilitates intraoperative planning; therefore, EUS-FNA is a golden standard method used to diagnose. Postoperative survival has improved if the tumor is completely removed. EUS-FNA technique is a minimally invasive technique that can provide high yielding in providing detailed diagnostic analysis of SPPN.
\end{abstract}

Keywords: Solid pseudo-papillary neoplasm, Pancreatic tumors, Endoscopic ultrasound, Fine-needle aspiration

\section{Introduction}

SPPN are rare pancreatic tumors that account for 0.2 to $2.7 \%$ of all pancreatic tumors [1] and 8 to $16 \%$ of pediatric pancreatic tumors [2]. This exocrine pancreatic neoplasm arises from undifferentiated pluripotent embryonal cells [3]. It has more predominance in females and mainly occurs in young adults between their second and third

\footnotetext{
*Correspondence: mohamed.elnady@kasralainy.edu.eg

${ }^{1}$ Department of Internal Medicine, Cairo University, Cairo, Egypt Full list of author information is available at the end of the article
}

decades. Although it is uncommon in men and extremes of age, it has a more aggressive and worse prognosis when present in men [4].

There are multiple nonspecific symptoms of SPPN including abdominal pain, nausea, jaundice, and palpable non-tender upper abdominal mass. Abdominal pain is the most common symptom, reported in more than one third of cases [5].

Various imaging techniques are used for the diagnosis of pancreatic neoplasms including transabdominal ultrasound (US), computerized tomography (CT), magnetic 
resonance imaging (MRI), and endoscopic ultrasound (EUS).

The EUS has been used widely in the diagnosis of pancreatic lesions, as it provides a better evaluation of the morphological characteristics of the lesions. In addition to the diagnosis, proper preoperative mapping of pancreatic resection is mandatory [6]. It offers the possibility of guiding fine needle aspiration (FNA) punctures with a low complication rate [7].

Complete surgical resection is the treatment of choice. It has an excellent long-term prognosis, since the tumor has an indolent behavior and a low malignant potential [2].

The SPPN could be solid, cystic, or mixed lesions; since these tumors do not induce a typical pattern on radiological examination, the preoperative diagnosis may be challenging in some cases [8].

\section{Aim of the study}

Our study describes a case series of 18 consecutive cases diagnosed with SPPN via preoperative EUS guided FNA, along with comparison of our analysis with the cases mentioned in the literature.

\section{Patients and methods}

The data of the patients presented to the EUS clinics in three medical centers: Cairo University, Mansoura University, and Assiut University in the period between January 2014 and December 2018 were prospectively collected. Before intervention, all cases were subjected to history taking, physical examination, and routine laboratory investigations (including tumor markers CEA and CA 19-9). Abdominal ultrasonography with triphasic abdominal CT or MRI was ordered for all cases before endoscopy.

An informed consent was obtained from all cases before the procedure after a complete explanation of its benefits and drawbacks. EUS was done Under deep sedation and the lesion was described regarding its site, size, echotexture, and relation to surrounding structures.

To get a biopsy sample by FNA, the trans duodenal route was used for head and uncinate process lesions, whereas the trans-gastric route was used for body and tail lesions. A needle was used to get the sample with at least 2 passes. The sample was sent for histopathological examination and immunohistochemical staining (IHC) when needed.

After diagnosis, radical resection of the tumors was done. The surgical specimen was sent for histopathological examination which confirmed the diagnosis of all cases. After operation, regular follow-up visits were scheduled for 1 and half year, at which clinical and radiological assessments (by abdominal US or CT) of cases were performed.

\section{Results}

The mean age of the included cases was 32.78 years. Most of the included cases were females (17 out of 18 cases, 94.44\%). All cases presented with abdominal pain while only three cases reported anorexia and weight loss. On examination, a palpable abdominal mass was detected in 4 cases $(22.22 \%)$.

Demographic description and patient characteristics are described in (Table 1).

The size of the detected lesions ranged between 3.5 and $13 \mathrm{~cm}$. Eight lesions were located in the body (44.44\%), while head lesions were detected in 7 cases (38.89\%). Besides, two cases $(11.11 \%)$ had tail lesions, whereas the uncinate process was affected in only one case $(5.56 \%)$ (Fig. 1).

The cytopathological study demonstrated single cells, small loose clusters, and scattered intact papillary structures with delicate fibrovascular cores, finely granular cytoplasm, and nuclei with fine chromatin.

Table 1 Data analysis of the patients' characteristics described in the study

\begin{tabular}{ll}
\hline Variable & Data $(\boldsymbol{n}=\mathbf{1 8})$ \\
\hline Age (year) & \\
Mean \pm SD & $32.78 \pm 16.272$ \\
Median (range) & $31(12-70)$ \\
Gender & \\
Male & $1(5.56 \%)$ \\
Female & $17(94.44 \%)$ \\
Presentation & \\
Pain & $18(100 \%)$ \\
Mass & $4(22.22 \%)$ \\
Anorexia and weight loss & $3(16.67 \%)$ \\
Size (mm) & \\
Mean \pm SD & $62.22 \pm 27.128$ \\
Median (range) & $(35-130)$ \\
Site & \\
Body & $8(44.44 \%)$ \\
Head & $7(38.89 \%)$ \\
Tail & $2(11.11 \%)$ \\
Uncinate process & $1(5.56 \%)$ \\
Operation & \\
Pancreaticoduodenectomy & $8(44.44 \%)$ \\
Distal pancreatectomy & $10(55.56 \%)$ \\
Mortality & $1(5.56 \%)$ \\
Follow-up duration & \\
Median in months (range) & $19(18-23)$ \\
\hline & $0(0 \%)$ \\
\hline
\end{tabular}




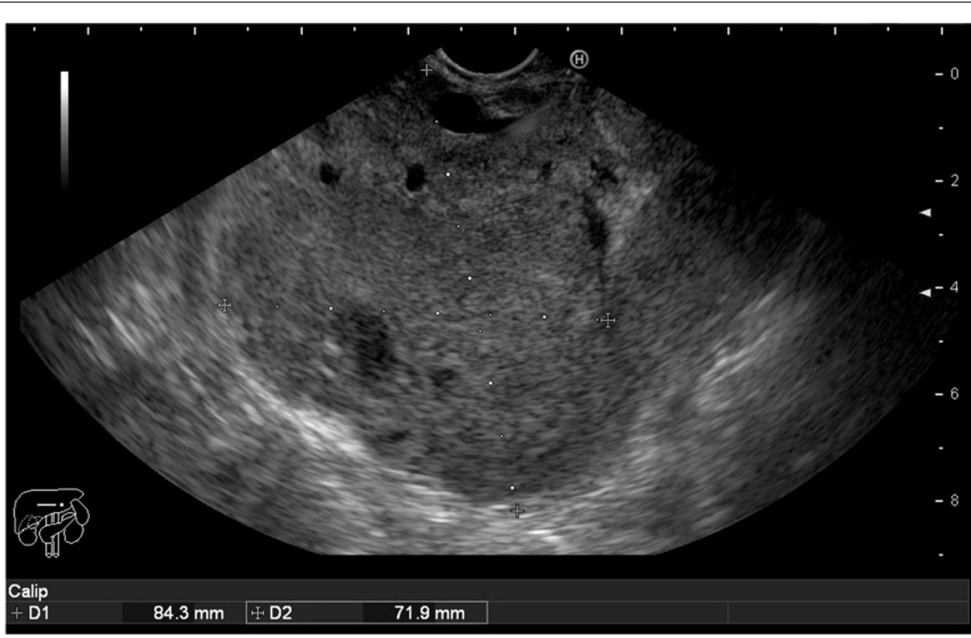

A

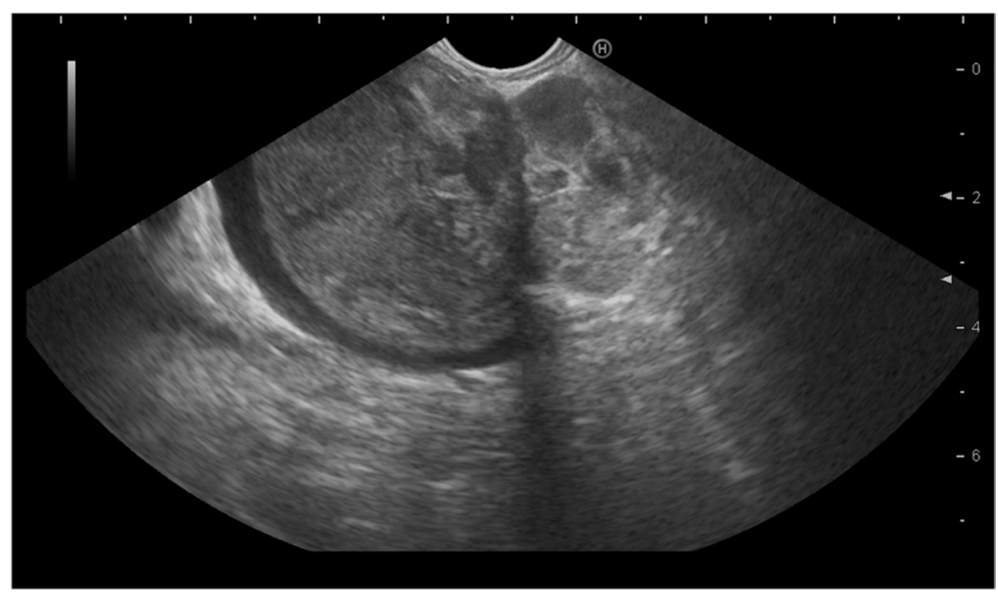

B

Fig. 1 EUS examination of solid-pseudopapillary neoplasm of the pancreas. A Mass in the head of the pancreas. The mass appears to be heterogenous mass with multiple small cysts (areas of breakdown). B EUS examination of a SPPN in the body of the pancreas seen compressing the confluence of the portal vein with no encroachment (clear line of cleavage)

The different histopathological results of EUS FNA samples examined by a well-trained cyto-pathologist and the different stains and immunohistochemistry examination are illustrated in (Fig. 2).

As regards the surgical procedure, pancreaticoduodenectomy was performed for head and uncinate process lesions, while distal pancreatectomy was performed for other distal lesions. Postoperative course was smooth in all cases, apart from one case (5.56\%) who underwent pancreatico-duodenectomy and died of abdominal sepsis secondary to anastomotic leakage. With at least 1 and half year of follow-up for cases, neither local nor distant recurrences were detected on subsequent imaging.

\section{Discussion and review of literature}

Frantz was the first to describe SPPN of the pancreas in 1959 [4]. It is an uncommon type of pancreatic tumor that exhibits benign characteristics in most of the cases reported, with a low tendency towards malignant behavior. It is usually discovered incidentally with a great predilection to occur in young women (about $90 \%$ of reported cases). However, it can affect men and women of any age group [9]. Other studies confirmed female predominance with a female to male ratio ranging from 5:1.9 [10] to 10:1 [11].

In the current series, most of the included cases were females (17 out of 18 cases, 94.44\%), and that agrees with the previously reported in the literature. Of note, the 


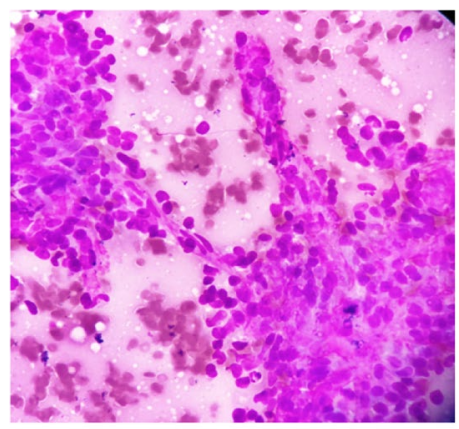

A

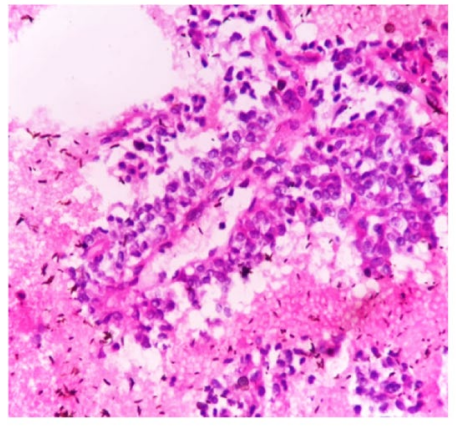

$\mathrm{C}$

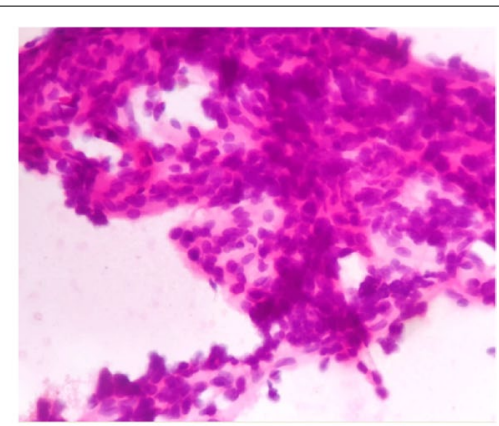

B

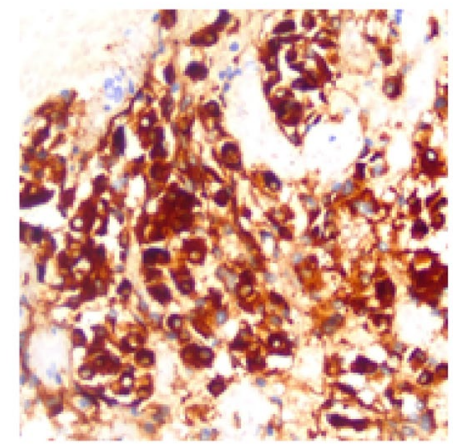

$\mathrm{D}$

Fig. 2 Histological examination of solid-pseudopapillary neoplasm of the pancreas. A DQ stain 400 power. B H\&E stain $\times 400$ power. C H\&E stain cell block preparation $\times 400$ power. Smears of adequate cellularity revealed solid cellular smear patterns formed of cells with small round to oval, occasionally grooved nuclei with finely granular even chromatin, and inconspicuous nucleolus with scant granular cytoplasm. Tumor cells surround myxoid vascular core stains magenta. D Immun-stain with CD10, $\times 400$ power; tumor cells showed diffuse positive immunoreactivity

oldest case in our series was 70 years old, and that is a proof that this tumor could be encountered at any age.

Regarding the presentation, about one third of cases could be asymptomatic. However, the presenting symptoms are usually non-specific. Abdominal pain is usually observed in $40 \%$ of cases. Other presenting symptoms include increased abdominal girth, jaundice (due to bile duct compression), anorexia, nausea, vomiting, and weight loss [5]. Some cases may present with acute abdomen due to capsule rupture [12]. In this study, abdominal pain was the main symptom, followed by abdominal mass, anorexia, and weight loss.

In our study, the size of the included lesions ranged between 3 and $13 \mathrm{~cm}$. Former study reported that the mean diameter of the tumor was $4.25 \mathrm{~cm}$ (range 1.2-6 $\mathrm{cm}$ ) [9]. A previous larger-scale study stated that tail and head are the commonest affected locations [2]. Our series revealed that pancreatic body was the most affected site, followed by head, tail, and uncinate process. The variance between different series could be explained by using different sample sizes between different reports.

Recently, SPPN has been increasingly diagnosed in clinical practice due to great advances of the exceptional imaging and endoscopic modalities. CT, MRI, and EUS are the most widely used investigations for the evaluation of pancreatic neoplasms [13]. SPPN usually appears like a well-vascularized mass with definite margins, calcifications, and necrotic hemorrhagic components [14]. In our series, all of the included cases underwent abdominal CT or MRI before the EUS procedure. Radiological measurement and site description were similar to EUS findings. Vascular assessment was more accurately evaluated by the EUS examination.

EUS-FNA is now considered the preferable type of diagnosis for pancreatic solid neoplasms. It has a highly noticeable diagnostic accuracy, and it is minimally invasive compared to regular biopsy [9]. It has a sensitivity ranging between 80 and $90 \%$, and a specificity ranging between 85 and $96 \%$ for diagnosing such lesions [15]. That agrees with our findings that were totally in line with the postoperative surgical specimen examination. SPPNs are identified by EUS as a well-circumscribed, solid, hypoechogenic, heterogeneous mass with cystic components and calcifications [16].

Histopathological examination of these lesions usually reveals pseudopapillary areas with fibrovascular stems or rosette-like structures secondary to weak neoplastic cell cohesion [17]. Immunohistochemical analysis shows 
positivity of these tumors towards beta-catenin, progesterone receptor, vimentin, neuron-specific coil, CD10, CD56, cyclin D1, E-membranous, and E-cadherin [5].

Abnormal nuclear expression of beta-catenin is the most sensitive specific marker for SPPN [18]. Moreover, the Ki-67 index has been used as an indicator of tumor malignant potential and poor prognosis. Slow tumor growth is anticipated with a low Ki-67 index $(\leq 5 \%)$ [19].

A previous study reported the superior efficacy of EUSFNA in the detection of pancreatic malignant neoplasms and the differentiation between neoplastic and non-neoplastic pancreatic cysts [20]. Law et al. previously published their case series regarding the same perspective and included a total of 34 cases. EUS-FNA was able to identify SPPN in $82 \%$ of patients versus $23.5 \%$ for abdominal CT findings and $41.2 \%$ for EUS alone [20].

No EUS related complications were reported in our series, and that coincides with the previous literature which states that complications are few and reported in only $1 \%$ of cases. These complications include acute pancreatitis, fever, abdominal pain, and bleeding [7].

Surgical resection of SPPN usually results in good outcome as the overall survival rate may reach $95 \%$. It is the main management option for SPPN $[5,9]$. The type of operation depends on the location of the tumor. If the head or uncinate process is affected, pancreaticoduodenectomy is performed [21], while distal or central pancreatectomy could be considered for tail and body lesions [22]. Our series showed that surgical option leads to good outcomes regarding survival, as during the follow-up period 18 months, no mortality was encountered, apart from the early mortality case due to abdominal sepsis after pancreaticoduodenectomy.

In the literature, the reported mortality rate following surgery for SPPN is only 1\% [2]. Pancreatico-duodenectomy is also one of the major pancreaticobiliary operations, with perioperative mortality ranging from 5 to $10 \%$ [23].

Although SPPN is known of its low malignant potential, metastasis could develop in up to $15 \%$ of cases [24]. Liver, inferior vena cava wall, and spleen constitute the commonest recurrence sites [24], while lymph node metastasis is rarely encountered [25, 26]. Furthermore, about $6 \%$ of cases could develop tumor recurrence. Therefore, a strict follow-up is mandatory [2]. In our series, no recurrence or metastasis was detected probably due to the relatively intermediate follow-up period, and small patient sample, respectively.

\section{Conclusion}

Solid Pseudo-Papillary Neoplasm is a rare pancreatic neoplasm. Affirming the type of tumor is of vital importance before surgery to provide an accurate intraoperative planning. EUS-FNA is a promising method with high potential to confirm the diagnosis of these lesions. Moreover, a good postoperative outcome is expected if the tumor is completely removed.

\section{Acknowledgements \\ Not applicable. \\ Authors' contributions \\ Hussein Okasha: Doing Endoscopic Ultrasound - Edition of Manuscript. Wael Abbas: Doing Endoscopic Ultrasound - Data Collection - Statistical Analysis. Ahmed Altonbary: Doing Endoscopic Ultrasound - Revision of Manuscript. Hazem Hakim: Doing Endoscopic Ultrasound. Mahmoud Gamal Ameen: Performing Histological Examination. Mohamed El-Nady: Doing Endoscopic Ultrasound - Edition of Manuscript - Revision and submission of Manuscript. The author(s) read and approved the final manuscript.}

\section{Funding}

No funding.

Availability of data and materials Yes, all data is available.

\section{Declarations}

\section{Ethics approval and consent to participate}

Not applicable (retrospective study based on analysis of available data). Yes, an informed consent was obtained from all cases.

\section{Consent for publication}

Yes, all authors approved submission of the manuscript for publication (available if requested).

\section{Competing interests}

The authors declare that they have no competing interests.

\section{Author details}

${ }^{1}$ Department of Internal Medicine, Cairo University, Cairo, Egypt. ${ }^{2}$ Department of Internal Medicine, Assiut University, Assiut, Egypt. ${ }^{3}$ Department of Internal Medicine, Mansoura University, Mansoura, Egypt. ${ }^{4}$ Department of Oncological Pathology, South Egypt Cancer Institute, Assiut University, Assiut, Egypt.

Received: 27 October 2021 Accepted: 29 December 2021 Published online: 24 January 2022

\section{References}

1. Branco C, Vilaca S, Falcao J (2017) Solid pseudopapillary neoplasm-case report of a rare pancreatic tumor. Int J Surg Case Rep 33:148-150

2. Papavramidis T, Papavramidis S (2005) Solid pseudopapillary tumors of the pancreas: review of 718 patients reported in English literature. J Am Coll Surg 200(6):965-972

3. Coleman KM, Doherty MC, Bigler SA (2003) Solid-pseudopapillary tumor of the pancreas. Radiographics 23(6):1644-1648

4. Lin MY, Stabile BE (2010) Solid pseudopapillary neoplasm of the pancreas: a rare and atypically aggressive disease among male patients. Am Surg 76(10):1075-1078

5. Yu P-F, Hu Z-H, Wang X-B et al (2010) Solid pseudopapillary tumor of the pancreas: a review of 553 cases in Chinese literature. World J Gastroenterol 16(10):1209

6. Park HY, Lee YJ, Lee JH et al (2013) Endoscopic ultrasound-guided fine needle aspiration of solid pseudopapillary tumors of the pancreas: a report of three cases. Korean J Intern Med 28(5):599

7. Eloubeidi MA, Varadarajulu S, Desai S et al (2007) A prospective evaluation of an algorithm incorporating routine preoperative endoscopic ultrasound-guided fine needle aspiration in suspected pancreatic cancer. J Gastrointest Surg 11(7):813-819 
8. Anil G, Zhang J, Al-Hamar NE, Nga ME (2017) Solid pseudopapillary neoplasm of the pancreas: $\mathrm{CT}$ imaging features and radiologic-pathologic correlation. Diagn Interv Radiol 23(2):94

9. Mirminachi B, Farrokhzad S, Sharifi AH et al (2016) Solid pseudopapillary neoplasm of pancreas; a case series and review literature. Middle East J Dig Dis 8(2):102

10. Choi J-Y, Kim M-J, Kim JH et al (2006) Solid pseudopapillary tumor of the pancreas: typical and atypical manifestations. Am J Roentgenol 187(2):W178-WW86

11. Mulkeen AL, Yoo PS, Cha C (2006) Less common neoplasms of the pancreas. World J Gastroenterol 12(20):3180

12. Mao C, Guvendi M, Domenico DR, Kim K, Thomford NR, Howard JM (1995) Papillary cystic and solid tumors of the pancreas: a pancreatic embryonic tumor? Studies of three cases and cumulative review of the world's literature. Surgery 118(5):821-828

13. Lubezky N, Papoulas M, Lessing Y et al (2017) Solid pseudopapillary neoplasm of the pancreas: management and long-term outcome. Eur J Surg Oncol 43(6):1056-1060

14. Fu XB, Hao ZQ, He JY et al (2017) Pathology comparative study on the characteristic CT signs in solid pseudopapillary neoplasm of the pancreas. Exp Ther Med 13(6):3523-3528

15. Banafea O, Mghanga FP, Zhao J, Zhao R, Zhu L (2016) Endoscopic ultrasonography with fine-needle aspiration for histological diagnosis of solid pancreatic masses: a meta-analysis of diagnostic accuracy studies. BMC Gastroenterol 16(1):108

16. Jung WS, Kim JK, Yu J-S, Kim JH, Cho E-S, Chung J-J (2014) Comparison of abdominal ultrasonographic findings with endoscopic ultrasonographic findings of solid pseudopapillary neoplasms of the pancreas. Ultrasound Q 30(3):173-178

17. Pettinato G, Carlos Manivel J, Ravetto C et al (1992) Papillary cystic tumor of the pancreas: a clinicopathologic study of 20 cases with cytologic, immunohistochemical, ultrastructural, and flow cytometric observations, and a review of the literature. Am J Clin Pathol 98(5):478-488

18. Tanaka Y, Kato K, Notohara K et al (2001) Frequent $\beta$-catenin mutation and cytoplasmic/nuclear accumulation in pancreatic solid-pseudopapillary neoplasm. Cancer Res 61(23):8401-8404

19. Yu P, Cheng X, Du Y et al (2015) Solid pseudopapillary neoplasms of the pancreas: a 19-year multicenter experience in China. J Gastrointest Surg 19(8):1433-1440

20. Law JK, Stoita A, Weaver W et al (2014) Endoscopic ultrasound-guided fine needle aspiration improves the pre-operative diagnostic yield of solid-pseudopapillary neoplasm of the pancreas: an international multicenter case series (with video). Surg Endosc 28(9):2592-2598

21. Naar L, Spanomichou D-A, Mastoraki A, Smyrniotis V, Arkadopoulos N (2017) Solid pseudopapillary neoplasms of the pancreas: a surgical and genetic enigma. World J Surg 41(7):1871-1881

22. Dokmak S, Aussilhou B, Paci M et al (2019) Extended laparoscopic central pancreatectomy with clamping of the mesentericoportal vein and resection of the splenic vessels for a large solid pseudopapillary tumor. Annals Surg Oncol 26(11):3709-3710

23. Kulemann B, Fritz M, GlatzT et al (2017) Complications after pancreaticoduodenectomy are associated with higher amounts of intra-and postoperative fluid therapy: a single center retrospective cohort study. Annals of Medicine and Surgery 16:23-29

24. Tang LH, Aydin H, Brennan MF, Klimstra DS (2005) Clinically aggressive solid pseudopapillary tumors of the pancreas: a report of two cases with components of undifferentiated carcinoma and a comparative clinicopathologic analysis of 34 conventional cases. Am J Surg Pathol 29(4):512-519

25. Goh BK, Tan YM, Cheow PC et al (2007) Solid pseudopapillary neoplasms of the pancreas: an updated experience. J Surg Oncol 95(8):640-644

26. Machado MC, Machado MAC, Bacchella T, Jukemura J, Almeida JL, Cunha JE (2008) Solid pseudopapillary neoplasm of the pancreas: distinct patterns of onset, diagnosis, and prognosis for male versus female patients. Surgery 143(1):29-34

\section{Publisher's Note}

Springer Nature remains neutral with regard to jurisdictional claims in published maps and institutional affiliations.

\section{Submit your manuscript to a SpringerOpen ${ }^{\circ}$ journal and benefit from:}

- Convenient online submission

- Rigorous peer review

- Open access: articles freely available online

- High visibility within the field

- Retaining the copyright to your article

Submit your next manuscript at $\boldsymbol{\nabla}$ springeropen.com 